\title{
A REVIEW ON DESIGN AND ANALYSIS OF COMPOSITE LEAF SPRING USING VARIOUS COMPOSITES
}

\author{
RAHEEM DOHAN OWAYEZ \& KHALDOON HUSSEIN HAMZAH
}

Department of Materials Engineering, College of Engineering, University of Al-Qadisiyah

\begin{abstract}
Leaf spring is one of the most critical ingredients in an automobile. Which is using in the suspension system, as it constitutes $10-20 \%$ of the weight of the vehicles, specifically the unsprung weight. Thus, leaf spring is one of the possible parts for weight reduction in the automobile. So the global an automobile manufacturer has shown increased interest in the competition to design optimization and improved manufacturing processes. Reduction in automobile weight can be achieved by using design optimization, better composite material and optimized manufacturing processes.

In this review paper, the emphasis was focus on the studies and research carried out on the leaf spring in the vehicle that aims to reduce weight and cost in the automobile manufacturing, put in this study according to the years of publication as reference for the researchers and for designers interested in this field.

KEYWORDS: Leaf Spring, Design, Composite Materials
\end{abstract}

Received: Jun 08, 2020; Accepted: Jun 28, 2020; Published: Aug 29, 2020; Paper Id.: IJMPERDJUN2020945

\section{INTRODUCTION}

Competition and progress continue in the current scenario in all fields, especially the automobile industry. Weight reduction is an important issue that occupies companies and researchers in many branches, especially in the automobile industry, that plays a significant role in this aspect in terms of reducing costs, and the cost of the automobile industry in terms of maintaining the environment by reducing fuel and reducing the energy consumed, of the other part. Therefore lowering the weight of automobile parts has become one of the most important problems that the researcher focuses on in terms of the use of alternative materials included in the manufacture of automobile parts. In addition, one of the important parts in cars is the suspension system, which is one of the parts that add. A decrease to the final weight of the vehicle by using of composite materials, which are manufactured to be an alternative to the alloys used in the manufacture of these parts while maintaining the quality of the mechanical properties with a reduction in weight. The leaf springs used to absorb shocks in vehicles is one of the important parts of the suspension system, which the improvement leads to good ride conditions and reduced weight and highquality mechanical and physical specifications such as energy, strength, flexibility, and density, etc.

\section{LITERATURE REVIEW}

The goal Primary of M. Sureshkumar, et al (2015) is to compare a composite leaf spring with steel leaf spring via load-carrying capacity, stiffness, by the saving of weight. The experimental study of hybrid fibre mono-leaf spring in a car has conducted, reinforced plastic type of Kevlar fibre and another reinforced plastic (Glass-fibre) was select. And compared the experimental data with conventional leaf spring. The results proved that GFRC can be chosen and can carry the max load, max. deformation and max stress. 
Adapa M. and B.Sreenivas (2015).The aim of this study is replacing multi-leaf by mono leaf spring, made composite material, under same load, stiffness and capacity except for the thickness. Used three materials E-glass, (CE) carbon/epoxy and (GE) graphite/epoxy. And modelling and analysis by using CATIA-5-19 and ANSYS 15-S. the results were in EGlass/ Epoxy the stress was lesser than the steel as well as in leaf spring.

AshviniP.lad et al (2015), the issue in this paper was to reduce weight to composite leaf spring made from the material of Epoxy-Carbon fibre by analysis of deflection and compared with a conventional leaf spring (steel) by using finite element analysis (FEA) by Ansys software. By giving $150 \mathrm{Kg} \mathrm{V}$-load each steps $50 \mathrm{Kg}$ in the middle of each spring, the result of the deflection was satisfactory comparing in the steel leaf, thus found $7 \%$ is acceptable, and there are identical with a suitable difference.

M. Gaffer Abbas (2016), et al, designed and analysis of leaf spring made from composite materials (Eglass/Epoxy) with reinforced polymer, the aim of this study was to get a new model to compare with steel leaf spring. In addition, a study of the effects of some parameters, as well the strength, stiffness, and reduce weight by using new materials. obtained recorded the lowest deflection to E-G-epoxy compared in the stresses and deflection in steel which It found has the max-deflection and stress, steel recorded lowest stress and deflection by (57.1\% and 51.7\%), respectively, While the epoxy decreased its weight by one ( $67.7 \%$ ) when compared to conventional steel leaf spring.

Thippesh L. (2016), replaced multi-leaf steel spring by the optimally designed composite one leaf spring, the mono spring made from composite glass fibre and reinforced plastic, with geometrical and mechanical properties similar to the conventional spring, The goal was for the lowest weight leaf spring to bear external loads With no failure, compare to tradition springs. Previous results obtained Composite materials had the lowest stresses, a higher natural frequency, compared in steel spring, also the spring weight is reduced in the new model.

Nagendra J (2016), Check if there were the damage by vibration parameters and validated with the experimental and numerical simulation. Observed that the difference in natural frequency in all parts, to found a crack except the forth because of its non-responsive nature. And observed that the variation in dynamic stiffness of cracked spring at the sixth location compared to healthy spring. was found that the maximum severity in fifth and sixth, the results were in a good agreement in experimental and numerical method after evaluated the parameters based on it, such as the presence, location and severity. the difference in natural frequency in all mode because finding a crack except the forth mode shape due to not responding, It was also observed that there was a significant difference with the dynamic stiffness of the damaged spring in the sixth mode compared to the healthy leaf spring, The max-severity found in the fifth mode and sixth mode. Through these results, and based on the parameters, the presence and risk were evaluated accurately and effectively, a good agreement in experimental and numerical has been found.

The goal of T. Gopalakrishnan, et al, (2017), in the existing research paper, to increase the stiffness of the spring used in the suspension system in the automobile a type of leaf spring, by using E-Glass /Graphite/Epoxy/Carbon, Instead of the conventional spring (steel leaf). The materials used are composite, were fabricated by inserting more fibre in the strengthening and reinforcement stage. So a new composite (hybrid composite) was obtained with good specifications, previous results obtained were increases and addition the stiffness of the new composite by the introduction of graphite fibre and carbon in the reinforcement phase. 
NahitOztoprak, et al (2017) Their goal was to find out the influence of the reinforcement type, orientation, and weight reduction in the spring. The mechanical properties of the various polymer materials obtained were evaluated experimentally after reinforcing with fibres, In this study, Abaqus 6.12 program was used to analyze data and obtain results to compare it with experimental results. These experimental results were compared to experimental tests of actual size. That was made on the prototypes, which were manufactured. After had studied results, they obtained a weight reduction of $80 \%$ with product improvement, especially mechanical properties, so can using the composite based springs in hybrid composite systems for with good mechanical performance.

Banka H. et al (2017). In this paper, the objective was design and analysis of a model, as a leaf spring made from composite materials E-glass- Epoxy reinforced polymer. To make a laminate for leaf spring to obtain a new design. And 3dimension model preparing by pro-E software by using ANSYS 14.5 Software A comparison was made between the steel spring and the new model. The hybrid composite spring (leaf) recorded the lesser cost, lesser stresses, lesser weight and higher stiffness.

Mr. V. J. Khot,et al (2018). Aims to the comparison of fatigue life evaluation of spring type of composite leaf, by the experiment analysis and numerical analysis methods. And used the Ansys Workbench to carry out numerical analysis, he found that leaf spring which is made from the composite materials is having infinite life, while experimental results was a good agreement with last results.

Harmeet Singh, Gurinder Singh Brar (2018). In this study, they compare two types of leaf spring. The first is composite materials as a metal matrix made of aluminium and carbon-epoxy. The second type is the spring used in the rear suspension system to Tata (small car), made of EN45A. The evaluation showed composite spring its a low weight and high strength and low density, compared with the EN45 steel, and there is matched between both the properties of EN45 steel leaf and composite materials, finally that an increasing the dimension and the weight raised a hardness of the model.

Mohammed I. Hameed et al (2018) studied the deflection and stresses for the spring as a leaf spring, which made from various materials (composite materials) and compared with the spring fabricated from steel. The materials used in this study are Boron-Aluminum composites, the first material carbon-Epoxy and another material E-glass-Epoxy. The deflection in leaf spring and stresses (Von-Mises) for the springs have been Calculated by using Ansys(FEA) 15.0 software. The spring made of composite materials was good as the heavy steel springs, also the results show that the reduction of $92 \%$ for the Carbon-Epoxy, $89 \%$ for the Boron-Aluminum and $85 \%$ for the Glass-Epoxy.

Ehab Samir Mohamed Mohamed Soliman (2019), in his research paper finite element analysis (FEA) is used to analyze the maximum load to Conventional spring as a leaf spring, in this study used ANSYS version-16 software. and compared with the results which was obtained from the leaf spring made composite materials from carbon fibre with epoxy resin( CFRP). the goals of the study were to obtain the same stiffness of that the steel one, the less weight, and safe design of composite leaf spring. After had studied the results, he obtained a weight reduction of $79 \%$ compared with conventional leaf spring, higher natural frequencies, and has a much higher factor of safety in stresses.

Kumar Verma et al (2019) tested a traditional spring, made of steel in the form of composite leaf for static loading condition. The steel spring was compared to other made of several materials (composite materials). 65Si7 (BIS) and EGlass/Epoxy are used to conventional steel spring and new leaf spring, respectively. By using Solidworks prepared the 3D model and then the analysis is performed by ANSYS 16.0. The results show that a great difference in the deflection and 
stresses in leaf spring compared composite leaf springs where the stresses in composite materials were less, and the deflection was more as compared to the steel leaf spring. as well with respect to weight ratio and strength, composite material found out to be less by $66.87 \%$. Therefore, considered the composite material to be the best and an effective replacement.

VikasKhatkar and B K Behera (2019) are studying the effect of inserting some materials as reinforcement in terms of mechanical performance of a spring made of composite materials due to the shape of a composite leaf. reinforcement form of E-Glass fibres (UD), (2D) woven and three-dimension orthogonal woven has been used In their research paper. The analysis is performed to composite leaf springs for tensile properties to Performance of 3D woven-based loaddeflection behaviour, Damping, relaxation behaviour, and strain rate sensitivity. The results showed that the threedimensional woven-based spring, much better than chopped uni-directional and bi-directional.

K. Umanath, et al (2020), fabricated the spring plate using three different materials by an open method. The primary layer was from the carbon fibre mat, the second from a polyepoxide, and the last layer from pineapple fiber mat. Calculated the Brinell hardness, impact strength, and compression strength to fiber (composite) and glass fibre reinforced leaf spring plate. From the results obtained from the comparison between the spring plate made up of carbon fibre and pineapple leaf fibre composites and the epoxy glass spring found that there are better strength and lighter weight in the carbon fibre and pineapple leaf fibre compare with the epoxy glass.

Jun Ke, et al (2020). The purpose of this study was to investigate and obtain calculations of the mainspring and auxiliary spring stiffness. The analysis is performed using the finite element (FEA) simulation and other related test results. the theoretical model is prepared, verified by the test results and the (FEA) simulation, thereafter reviews on the effect of important parameters to the spring(composite leaf)with the mainspring and an assistant spring, on the design parameters that influence the stiffness of leaf spring. The study conclusions were for the theoretical model there is a possibility for optimizing the design, therefore, the development steps of leaf spring with a mainspring and an assistant spring significantly. In addition, a new think of numerical calculation for the stiffness problem can be provided.

A Belyaeva and Evseev (2020). In this study paper, the leaf spring made from polymeric composite materials is analyzed. analysis of elastic properties is performed using by finite element method (FEA) After analyzing the results, they have obtained the maximum deflections of the leaf spring was impossible to use the leaf spring in a GAZ-2752 car as the suspension system.

\section{CONCLUSIONS}

The main objective of this paper is to provide a summary of the work and research presented in the field of design and analysis of leaf springs in order to obtain lower weight and good mechanical specifications and thus reduce the weight of vehicles and keep fuel and energy consumption. The researchers provided many methods and materials used for that purpose, increase the capacity, stiffness and strength of the composite leaf spring. using experimental and analytical methods by software packages such as PRO-E, CATIA, CAE, Abaqus, ANSYS. After had studied the various research papers. We found less weight and stresses in composite materials compared with conventional leaf spring. Also, ride comfort. An increase in strength and fatigue life. All this ensures a promising future for vehicles and is considered a successful and effective alternative to mechanical parts in vehicles, also, it is possible to identify potential substances that replace conventional metal springs while not give up strength and well reduction structural weight. 


\section{REFERENCES}

1. M. Sureshkumar, Dr. P.Tamilselvam, G. Tharanitharan, Experimental Investigation of Hybrid Fiber Mono Composite Leaf Spring for Automobile Applications, International Journal of Mechanical Engineering and Research, ISSN 0973-4562 Vol. 5 No.1 (2015), pp(89-93).

2. Adapa. Mahanth Kumar, B. Sreenivasa Kumar Reddy, Modeling and Analysis of Mono Composite Leaf Spring under the Dynamic load condition using FEA for LCV, International Journal of Science and Research (IJSR), Volume 4 Issue 6, June $2015 p p(2135-2141)$.

3. AshviniP.lad, Prof.B.S. Gandhare, Prof.A.S.Aradhye, Prof.N.V.Hargude, Deflection Analysis of Steel Leaf Springvs Composite Leaf Spring Through FEA Software, International Journal of Application or Innovation in Engineering \& Management (IJAIEM), Volume 4, Issue 4, April 2015, pp(1-8).

4. Juliyana, S. Jebarose, et al. "Finite Element Analysis of Mono Composite Leaf Spring of Varying Thickness and Varying Width used in Automotives." Int Journal of Mechanical and Production Engineering Research and Development 7.6 (2017): $247-$ 254.

5. M. KamaleldinGaffar Abbas et al, Design and Numerical Analysis of Leaf Spring Using Composite Materials, Key Engineering Materials Submitted, Vol. 723, pp 305-310, Proceedings of International Conference on Material Science and Engineering 2016.

6. Thippesh L, Fabrication of Hybrid Composite Mono-Leaf Spring with Unidirectional Glass Fibers, International Conference on Advanced Materials and Applications (ICAMA 2016),Materials Today: Proceedings 5 (2018) 2980-2984.

7. Nagendra Iranna Jamadar, et al, Detection and Quantification of Crack in Composite Mono Leaf Spring by Vibration Parameters, Journal of The Institution of Engineers (India): Series C, DOI 10.1007/s40032-016-03150(2016).

8. Karlus, Edward Nikhil, Rakesh L. Himte, and Ram Krishna Rathore. "Optimization of mono parabolic leaf spring." International Journal of Advances in Engineering \& Technology 7.1 (2014): 283.

9. T Gopalakrishnan et al 2017 IOP Conf. Ser.: Mater. Sci. Eng. 183 012004, Design and Fabrication of E-Glass /carbon/graphite epoxy hybrid composite leaf spring.

10. NahitOztoprak, Mehmet DenizGunes, MetinTanoglu, EnginAktas, OguzOzgurEgilmez, CilerSenocak and GedizKulac, SciEng Compos Mater 2018; 25(6): 1167-1176, https://doi.org/10.1515/secm-2016-0335.

11. Kalwaghe, Rupesh N., and K. R. Sontakke. "Design and Anslysis of composite leaf spring by using FEA and ANSYS." International journal of scientific engineering and research 3.5 (2015): 74-77.

12. Banka, H., Muluka, R., and Reddy, V., "Fabrication and Experimental Analysis of Epoxy-Glass Fiber Composite Leaf Spring," SAE Technical Paper 2017-28-1985, 2017, doi:10.4271/2017-28-1985.

13. Mr. V. J. Khotl, et al, Fatigue Life Evaluation of Composite Material Leaf Spring- Numerical and Experimental Approach, International Research Journal of Engineering and Technology (IRJET), Volume: 05 Issue: 12 | Dec 2018, pp(1139-1143).

14. Dewanji, Pinaknath. "Design and analysis of composite leaf spring." International Journal of Mechanical Engineering and Technology 7.5 (2016): 2016.

15. HarmeetSingha, Gurinder Singh Brarb, Characterization and Investigation of Mechanical Properties of Composite Materials used for Leaf Spring, Materials Today: Proceedings 5 (2018) 5857-5863,7th International Conference of Materials Processing and Characterization, pp(5858-5863). 
16. Mohammed I. Hameed, Dhia A. Alazawi, Zaid S. Hammoudi, Finite Element Analysis of Steel and Composite Leaf Springs Under Static Loading, International Scientific Conference of Engineering Sciences-3rd Scientific Conference of Engineering Science (ISCES),(2018), pp(181-185).

17. Ehab Samir Mohamed Mohamed Soliman, Static and Vibration Analysis of CFRP Composite Mono Leaf Spring, Journal of Failure Analysis and Prevention, (2019) 19:5-14.

18. Kumar Verma, Asst. Prof. Mukesh Hemnani, Asst. Prof. Rakesh Sharma, Comparative Analysis of Multi-Leaf Spring and Composite Leaf Spring using Finite Element Method Under Static Loading Condition, International Journal of Scientific Research \& Engineering Trends Volume 5, Issue5, Sep-Oct-2019, pp(1596-1503).

19. VikasKhatkar\& B K Behera (2019): Experimental investigation of composite leaf spring reinforced with various fiber architecture, Advanced Composite Materials, DOI: 10.1080/09243046.2019.1649952.

20. K. Umanath, M. K. Prabhu, A. Yuvaraj et al., Fabrication and analysis of Master leaf spring plate using carbon fibre and pineapple leaf fibre as natural composite materials,MaterialsToday:Proceedings,https://doi.org/10.1016/j.matpr.2020.03.790.

21. Jun Ke, Chen Qian et al., A theoretical model used for determining the stiffness of composite leaf springs with a main spring and an auxiliary spring, Journal of the Brazilian Society of Mechanical Sciences and Engineering (2020) 42:58 https://doi.org/10.1007/s40430-019-2138-4.

22. AABelyaeva and K B Evseev, Materials Science and Engineering 709 (2020) 033011, doi:10.1088/1757-899X/709/3/033011. 